LIMA, M. A. Qualidade e segurança do morango produzido nos sistemas: convencional, orgânico e produção integrada. Revista Agrogeoambiental, Pouso Alegre, v. 7, n. 4, p. 47-57, dez. 2015.

\title{
Q Qualidade e segurança do morango produzido nos sistemas convencional, orgânico e produção integrada
}

Maria Aparecida Lima ${ }^{1}$

\section{Resumo}

O morango (Fragaria x ananassa) é uma infrutescência de grande aceitação comercial por sua aparência, aroma e sabor atrativo. No Brasil, o morango tem sido produzido de acordo com três sistemas: Produção Convencional (sistema tradicional de cultivo, não regido por normas específicas); Produção Integrada de Morango (PIMo) e Produção Orgânica, sendo os dois últimos sistemas de certificação por adesão voluntária regidos por normas técnicas específicas. O objetivo do presente estudo foi avaliar a qualidade pós-colheita e segurança alimentar de morangos da variedade Oso Grande, oriundos desses diferentes sistemas de produção. Vinte e sete amostras de morango provenientes de nove produtores diferentes, já embaladas em bandejas de tereftalato de polietileno (PET), com capacidade de 300 a 400g, foram avaliadas. A avaliação abrangeu a segurança do alimento, a análise multirresíduo de produtos autorizados pelo Ministério da Agricultura e de alguns não autorizados, detectados pela ANVISA, e a qualidade pós-colheita (análises físico-químicas). Os produtos do sistema convencional apresentaram, em ambas as safras, resíduos de produtos não autorizados para a cultura, portanto, inseguros para o consumo. Os morangos orgânicos, nas safras de 2010 e 2011 , e PIMo, na de 2010, apresentaram-se seguros ao consumo. Os morangos produzidos nos sistemas orgânico, integrado e convencional mostraram-se iguais quanto à qualidade pós-colheita.

Palavras-chave: Pós-colheita. Alimento seguro. Vida de prateleira. Resíduo.

\section{Introdução}

O morango (Fragaria ananassa) é um pseudofruto altamente perecível, em decorrência das propriedades fisiológicas e morfológicas que resultam em curta vida de prateleira (ALMENAR et al., 2009), frequentemente estimada em até cinco dias, pela sua rápida desidratação, escurecimento, lesões mecânicas e incidência de doenças causadas por vários patógenos (SALLATO et al., 2007). A produção de morango é afetada por grande número de pragas e doenças, o que leva muitos produtores a adotar práticas inadequadas, como o uso excessivo de agrotóxicos. A análise multirresíduo de pesticidas em frutas, hortaliças e outros produtos é um procedimento comum em todo o mundo para a regulamentação da segurança do alimento, comércio internacional, avaliação do risco toxicológico e investigações de pesquisa (LEHOTAY et al., 2011).

A agricultura sustentável é baseada no princípio de que as práticas agrícolas devem atender às necessidades dos consumidores, sem comprometer a capacidade de as gerações futuras satisfazerem suas próprias necessidades. Pensando nesse princípio, sistemas de produção são projetados para promover o desenvolvimento e manter a sustentabilidade (ASAMI et al., 2003).

A qualidade pós-colheita dos frutos é determinada por fatores varietais, edafo-climáticos, práticas culturais, estado fisiológico do fruto na colheita, tecnologia de colheita, manuseio e condições de armazenamento pós-colheita (SOUSA, 2000).

1 Centro de Engenharia e Automação/IAC, pesquisadora científica. Jundiaí, SP, Brasil. malima@iac.sp.gov.br. Caixa Postal 26, CEP 13212-970, Jundiaí-SP. 
Segundo Santos (2007), a variedade Oso Grande é de dias curtos e de grande adaptabilidade. Trata-se de uma planta vigorosa, com folhas grandes e de cor verde-escura, com ciclo mediano e elevada capacidade produtiva. Apresenta frutos de tamanho grande, polpa de textura firme no início da produção e mediana no final da colheita, de cor vermelho-clara e aromática; epiderme vermeIho-clara; sabor subácido, próprio para consumo in natura. Alves (2009) avaliou as características físico-químicas da variedade Oso Grande e encontrou, em média, pH 3,69, sólidos solúveis (SS) de 7,70 Brix, acidez titulável (AT) 1,13mg ácido cítrico.100g-1 de morango. Pelayo et al. (2003) encontraram acidez titulável de algumas variedades de morango que variava de 0,77 a 1,0mg ácido cítrico $100 g^{-1}$ de morango.

No Brasil, a permissão de uso de agrotóxicos está condicionada a vários estudos, entre eles a toxicidade avaliada pela determinação do limite máximo de resíduo (LMR) estabelecido pela Agência Nacional de Vigilância Sanitária (ANVISA). O LMR é definido como "a quantidade máxima de resíduo de agrotóxico oficialmente aceita no alimento, em decorrência da aplicação adequada numa fase específica, desde sua produção até o consumo, expressa em partes do agrotóxico, afim ou seus resíduos por milhão de partes de alimento (ppm ou $\mathrm{mg} / \mathrm{kg}$ )". Internacionalmente, os LMRs são estabelecidos por órgãos subordinados às Nações Unidas, como: Food and Agricultural Organization (FAO), World Health Organization (WHO) e o CODEX Alimentarius Mundial (CODEX, 2013).

Apesar da utilidade de agrotóxicos nas práticas agrícolas, são crescentes as preocupações sobre seu uso excessivo e níveis residuais no ambiente e nos alimentos. A produção integrada (PI) foi adotada para maximizar a produtividade da cultura, mantendo ao mesmo tempo a qualidade do ambiente em relação à contaminação e à sustentabilidade (FERNANDES et al., 2011).

Magkos et al. (2006) relatam que o consumidor se preocupa cada vez mais com a qualidade dos alimentos e com a segurança e a proteção do meio ambiente. A preferência por alimentos que ofereçam vantagens terapêuticas tem levado o consumidor a buscar produtos agrícolas cultivados organicamente (FERNANDES et. al, 2012). Considere-se, ainda, que o morango é uma boa fonte de antioxidantes naturais, como antocianinas, flavonoides e ácidos fenólicos (JIN et al., 2012).

Alguns autores observaram que frutas de produção orgânica continham nível significativamente mais elevado de fitoquímicos do que as produzidas de forma convencional (ASAMI et al., 2003; LAIRON, 2010; JIN et al., 2012). No entanto, outros autores relatam que não há provas suficientes que comprovem que os alimentos orgânicos são superiores em qualidade nutricional e segurança (BOURN; PRESCOTT, 2002, MAGKOS et al., 2003; AMODIO, et al., 2007, DANGOUR et al., 2010).

Ferreira et al., (2010) observaram, em tomate de cultivo convencional, manutenção de massa fresca significativamente superior ao orgânico e comportamento similar quanto aos teores de sólidos solúveis, acidez titulável e pH. Louarn et al. (2012) compararam a susceptibilidade de doenças em cenouras cultivadas pelos sistemas convencional e orgânico durante armazenamento pós-colheita. Observaram que a incidência de doenças em cenouras de cultivo orgânico foi significativamente maior do que nas cultivadas de forma convencional. Maffei et al. (2013) avaliaram 130 amostras de diferentes variedades de vegetais comercializados no Brasil, quanto à qualidade microbiológica, e observaram que alguns produtos orgânicos apresentavam maior carga microbiana que os convencionais, porém os resultados globais mostraram que essa não é uma tendência. Concluíram que são necessárias boas práticas agrícolas e higienização adequada antes do consumo para garantir a qualidade e segurança do alimento.

Segundo Winter e Davis (2006) e Luthria et al. (2010), é prematuro concluir que alimentos orgânicos ou convencionais são melhores em termos de segurança ou valor nutricional. Giampieri 
et al. (2012) citam a genética como o principal fator na determinação da qualidade nutricional dos frutos, assim como as condições de cultivo (ambiente e técnicas), época de maturação e cuidados pré e pós-colheita.

O morango apresenta diversas formas de cultivo. No Brasil, os sistemas mais comuns são:

1) Convencional: a produção tradicional não é regida por normas específicas, porém busca adotar as boas práticas agrícolas, obedecendo à legislação brasileira vigente;

2) Produção Integrada de Morango (PIMo): a Produção Integrada é um programa de avaliação da conformidade, desenvolvido pelo Instituto Nacional de Metrologia (INMETRO), que emprega normas técnicas específicas de cultivo elaboradas sob a coordenação do Ministério da Agricultura, Pecuária e Abastecimento (MAPA). Esse programa tem como foco a qualidade, priorizando a sustentabilidade, a aplicação de recursos naturais, a substituição de insumos poluentes, o monitoramento dos procedimentos e a rastreabilidade de todo o processo, tornando-o economicamente viável, ambientalmente correto e socialmente justo. Seu objetivo é substituir as práticas convencionais onerosas por um processo que possibilite a diminuição dos custos de produção, a melhoria da qualidade, a redução nos danos ambientais e o aumento do grau de credibilidade e confiabilidade do consumidor (MAPA, 2009).

3) Produção Orgânica: a agricultura orgânica visa ao estabelecimento de sistemas agrícolas ecologicamente equilibrados e estáveis. Não é permitido o uso de agrotóxicos e fertilizantes químicos, e o controle de pragas e doenças só pode ser realizado com produtos naturais. A obtenção de certificação ou selo pode ocorrer por contratação de certificadora acreditada no INMETRO ou por processos participativos de certificação, em que há uma relação de envolvimento e confiança entre produtores e consumidores, com acompanhamento cuidadoso do processo produtivo, que deve estar em conformidade com as normas oficiais de produção orgânica.

O objetivo do presente estudo foi avaliar a qualidade pós-colheita e a segurança do morango, em função do tipo de cultivo no Brasil, de frutos provenientes dos sistemas convencional, produção integrada (PIMo) e orgânico.

\section{Material e métodos}

Morangos da cultivar Oso Grande foram adquiridos em pomares comerciais de Atibaia, Jarinu e Valinhos, estado de São Paulo, nas primeiras horas do dia, com 50-75\% da superfície de cor vermelho-brilhante, conforme recomendação de Cantillano (2005). Os frutos foram adquiridos nos locais de produção já classificados e embalados em bandejas de tereftalato de polietileno (PET) com capacidade de 300 - 400g. Foram adquiridas 160 bandejas de cada produtor. Essas amostras foram identificadas, acondicionadas em caixa de papelão e cuidadosamente transportadas para o laboratório de Pós-Colheita do Centro de Engenharia e Automação, onde foram separadas em duas partes: 50 bandejas para análises pós-colheita e 110 para análise de resíduo de agrotóxicos.

O experimento foi realizado durante a safra 2010 e repetido em 2011, utilizando frutos provenientes de 9 propriedades, sendo 3 convencionais, 3 de produção integrada e 3 orgânica. Os morangos do sistema orgânico foram comprovados por certificação apresentada pelo produtor, os de PIMo, pelo credenciamento no Programa coordenado pela Embrapa Meio Ambiente, que estavam em processo de certificação, e os do sistema convencional, porque assim se declararam. 


\section{Análise de resíduo}

A análise de resíduo foi realizada pelo Laboratório Agrosafety Monitoramento Agrícola Ltda, acreditado pelo INMETRO, por GC/MS e LC/MS pelo escopo de acreditação ABNT NBR ISO/IEC 17025, sob número CRL 0286.

Para essa análise, separou-se 1,5kg de morango (aproximadamente 4 bandejas), que foi acondicionado em sacos plásticos, em seguida lacrados e identificados, por sistema de produção e repetição, e imediatamente enviados para o laboratório.

$\mathrm{Na}$ análise multirresíduos, avaliou-se na safra 2010, e repetiu-se em 2011, a presença e os conteúdos de produtos registrados para a cultura do morango (MAPA, 2010) e de produtos não autorizados, mas que foram encontrados nos últimos relatórios divulgados pela ANVISA, por meio do Programa de Análise de Resíduos de Agrotóxicos nos Alimentos (PARA), em 2008 e 2009 (JARDIM; CALDAS, 2012).

\section{Análises pós-colheita}

As bandejas destinadas para avaliação pós-colheita foram separadas e identificadas em dois grupos, sendo cada bandeja uma unidade experimental; foram feitas análises destrutivas e não destrutivas.

Nas análises não destrutivas (físicas), cada tratamento (sistema de produção, com 3 repetições) foi integrado de 9 bandejas para as avaliações diárias durante todo o experimento.

Nas análises destrutivas (químicas), cada tratamento (sistema de produção, com 3 repetições) foi integrado de 12 bandejas para serem amostradas e analisadas quimicamente a cada dois dias.

Essas bandejas foram armazenadas em estufa B.O.D. com temperatura e umidade controlada, simulando condição ambiente $\left(23 \pm 2^{\circ} \mathrm{C}\right.$ e $65 \pm 5 \%$ UR), no laboratório de pós-colheita e, periodicamente, avaliadas física e quimicamente.

\section{Análises físicas}

Para análise da perda de massa fresca acumulada, os frutos tiveram a massa fresca avaliada diariamente quanto à perda, baseada na diferença de massa inicial dos frutos (início do armazenamento) e a massa nas datas das avaliações, por meio de balança semianalítica (Marte-AS5500c). Os resultados foram expressos em porcentagem.

Quanto à análise de incidência de podridões, todos os frutos de cada bandeja foram avaliados por meio de observações visuais, considerados doentes aqueles que apresentavam lesões características. Os resultados foram expressos em porcentagem.

\section{Análises químicas}

O teor de Acidez Titulável (AT) foi doseado em 10g de material previamente triturado e homogeneizado em $50 \mathrm{~mL}$ de água destilada, por meio de titulação com $\mathrm{NaOH}$ a $0,1 \mathrm{M}$ padronizada, tendo como ponto de viragem $\mathrm{pH}=8,2$. Os resultados foram expressos pelo equivalente em miligramas de ácido cítrico por 100 gramas de amostra (AOAC, 1997).

Para avaliar o teor de sólidos solúveis (SS), fez-se a análise em gotas do material triturado, medido em refratômetro digital marca Atago, com resultados expressos em Brix (AOAC, 1997). 
O valor de $\mathrm{pH}$ foi determinado por potenciometria e medido após imersão direta do eletrodo de vidro no material previamente triturado.

A relação SS/AT foi determinada pela razão obtida entre o teor de sólidos solúveis (expressos em ${ }^{\circ}$ Brix) e a AT, cujo nome é Ratio. Essa razão determina se o fruto apresenta, em termos de sabor, as qualidades referentes ao bom paladar (combinação agradável de açúcar e acidez).

\section{Delineamento estatístico}

O delineamento estatístico utilizado para as análises pós-colheita de $\mathrm{pH}, \mathrm{SS}$, AT e SS/AT foi feito em blocos inteiramente casualizados (DBC) $3 \times 3$ com 3 repetições, sendo 3 tratamentos (produção convencional, orgânica e integrada) e 3 datas de avaliação. Para o parâmetro massa fresca, foi utilizado o mesmo delineamento, mas em 5 datas de avaliação. Os dados foram submetidos à análise de variância pelo teste $\mathrm{F}$ e as médias foram comparadas pelo teste de Tukey a $5 \%$ de probabilidade, utilizando-se o programa Assistência Estatística (ASSISTAT), descrito por Silva e Azevedo (2009).

\section{Resultados e discussão}

\section{Resíduos}

Na Tabela 1, pode-se observar que, na safra de 2010, no sistema convencional, foi detectado o uso de Folpete, produto de ação fungicida não autorizado para o morango. Nessa mesma safra, os morangos dos sistemas PIMo e orgânicos atenderam às normas do sistema produtivo e se apresentaram conformes.

Na safra 2011, nas amostras de morangos produzidos segundo os sistemas de cultivo convencional e PIMo, foram detectados resíduos de carbendazim e clorfenapir, produtos também não autorizados para a cultura. Ressalte-se, porém, que o carbendazim é um dos metabólitos da degradação do tiofanato-métilico (produto autorizado para morango), por isso, segundo a ANVISA, para fins de monitoramento de resíduos, devem ser considerados os LMRs do tiofanato-metilico, e os resultados desses foram interpretados como satisfatórios.

A detecção de 0,14 mg/kg de Clorfenapir nos morangos do sistema PIMo indicou uma não conformidade desses produtores, tendo em vista que buscam a certificação, necessitando se adequarem às normas do sistema produtivo. Esses produtores alegaram cultivar outras plantas nas quais 0 Clorfenapir é autorizado, o que provavelmente os levou à falha no manejo das culturas. 0 ocorrido deixou os produtores sob alerta no atendimento adequado às normas do sistema produtivo, fato que será crucial na obtenção do selo, já que passarão pelo crivo de uma certificadora para avaliação da conformidade do sistema produtivo. No sistema convencional, foram detectadas duas irregularidades: LMR de Ipridiona, acima do permitido para morangos, e ocorrência de Clorfenapir, que não é autorizado. Nesse último caso, o produtor também cultiva plantas para as quais ele é permitido.

Os frutos provenientes do sistema de cultivo orgânico não apresentaram resíduos de agrotóxico nas duas safras avaliadas, indicando boas práticas desses produtores, assim como comprometimento com o sistema de cultivo. 
Tabela 1. Valores médios de resíduos de agrotóxicos encontrados em amostras de morango produzidos em sistema de produção convencional, integrado e orgânico nas safras de 2010 e 2011.

\begin{tabular}{|c|c|c|c|c|c|}
\hline \multirow[b]{2}{*}{ Ingrediente ativo } & \multirow[t]{2}{*}{ Ação } & \multicolumn{3}{|c|}{ Resultados (mg/kg) } & \multirow{2}{*}{$\begin{array}{l}\mathrm{LMR}^{(1)} \\
(\mathrm{mg} / \mathrm{kg})\end{array}$} \\
\hline & & Convencional & PIMo & Orgânico & \\
\hline \multicolumn{6}{|l|}{ SAFRA 2010} \\
\hline Fluazinam & Fungicida/acaricida & 0,108 & - & - & 2,0 \\
\hline Folpete & Fungicida & 0,0105 & - & - & $N A^{(2)}$ \\
\hline Dodine & Fungicida & $<0,01$ & - & - & 5,0 \\
\hline Procimidona & Fungicida & 0,06 & 0,423 & - & 3,0 \\
\hline Pirimetanil & Fungicida & 0,37 & $<0,01$ & - & 1,0 \\
\hline \multicolumn{6}{|l|}{ SAFRA 2011} \\
\hline Ipridiona & Fungicida & 2,18 & 0,01 & - & 2,0 \\
\hline Procimidona & Fungicida & 1,12 & 1,85 & - & 3,0 \\
\hline Pirimetanil & Fungicida & 0,28 & 0,03 & - & 1,0 \\
\hline Carbendazim & Fungicida & 0,42 & 0,2 & - & 0,5 \\
\hline Tiofanato-metilico & Fungicida & 0,06 & - & - & 0,5 \\
\hline Azoxistrobina & Fungicida & 0,05 & 0,05 & - & 0,3 \\
\hline Difenoconazol & Fungicida & 0,03 & 0,05 & - & 0,5 \\
\hline Clorfenapir & Inseticida/Acaricida & 0,02 & 0,14 & - & $N A^{(2)}$ \\
\hline Propargite & Acaricida & 0,23 & 0,05 & - & 0,5 \\
\hline
\end{tabular}

(1) Limite Máximo de Resíduo, (2) Não Autorizado

Fonte: Elaboração da autora.

\section{Qualidade pós-colheita}

Os valores médios de perda de massa fresca (Figura 1), independente do sistema de cultivo, foram graduais durante o período de armazenamento, não se observando diferença significativa entre os tratamentos, tanto na safra de 2010 quanto na de 2011. A perda de massa dos frutos é associada, principalmente, à perda de água ocasionada tanto pela transpiração como pela respiração das frutas (SILVA et al. 2006). Esse resultado discorda do encontrado por Ferreira et al. (2010) para tomate, segundo o qual os frutos do sistema convencional apresentaram melhor manutenção que os do orgânico.

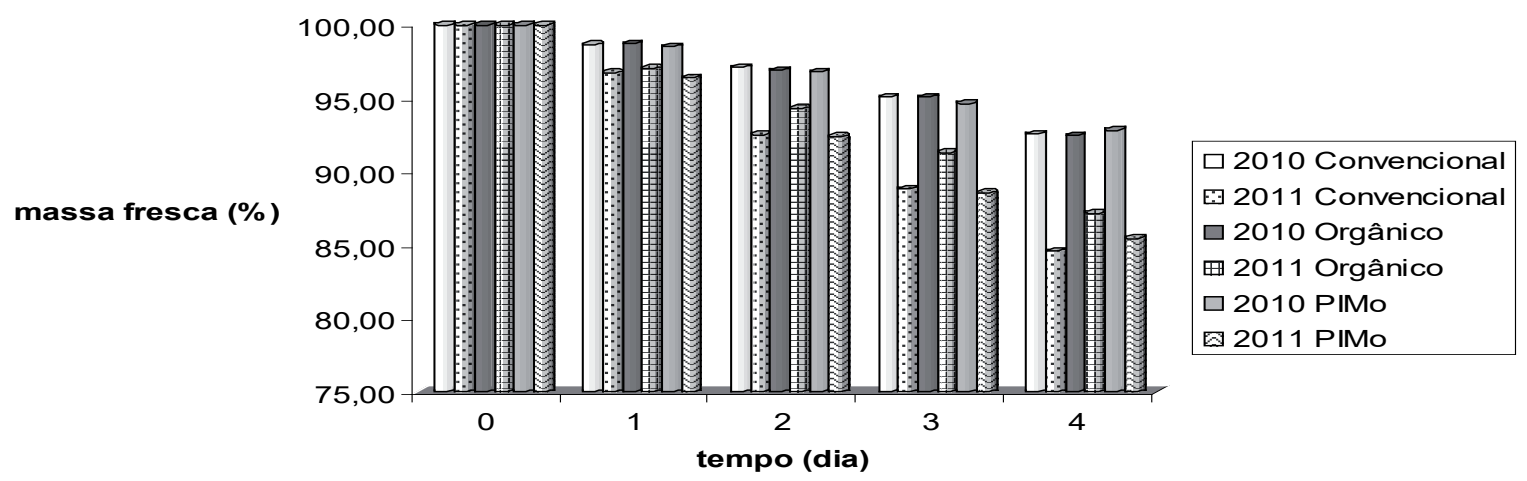

Figura 1. Valores médios de perda de massa fresca em morangos oriundos de sistema de produção convencional, orgânico e integrado nas safras de 2010 e 2011.

Fonte: Elaboração da autora.

Na safra 2010, o morango orgânico apresentava, no terceiro dia de armazenamento, 33,97\% de incidência de podridão, seguido de $26,79 \%$ no convencional e $4,42 \%$ no PIMo. 0 mesmo resultado foi 
observado na safra 2011, quando os frutos apresentaram 23,15\% de incidência de podridões, seguido de 15,48\% no convencional e 11,32\% no PIMo (Figura 2). A maior incidência nos morangos orgânicos pode estar relacionada ao observado por Maffei et al. (2003): maior carga microbiana vinda do campo nesses produtos. Louarn et al. (2012), em cenouras, e Maffei et al. (2013), em vários vegetais, também observaram maior incidência de podridões em produtos orgânicos em comparação aos convencionais.

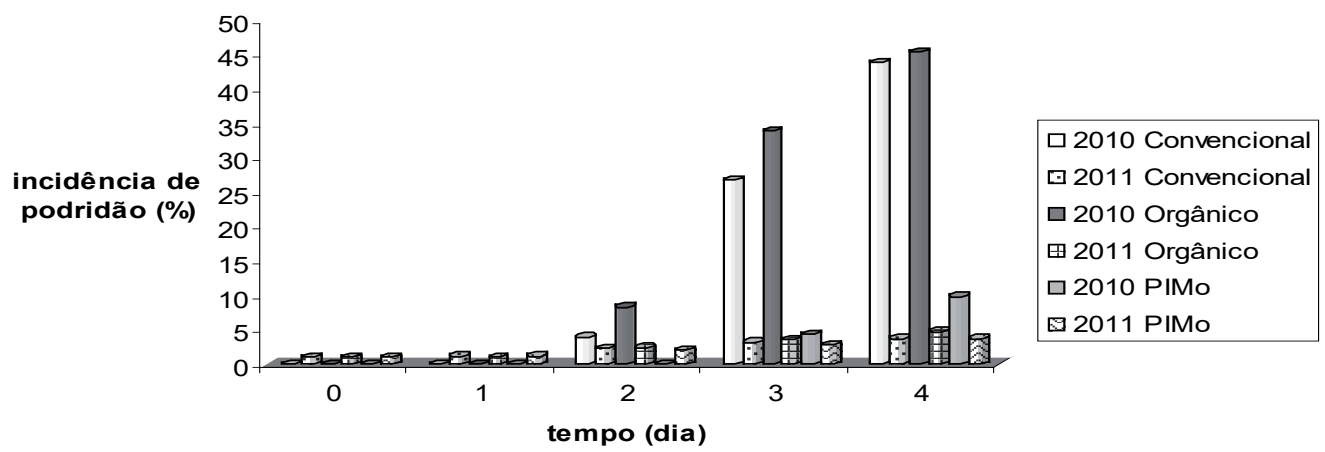

Figura 2. Valores médios de incidência de podridões em morangos oriundos de sistema de produção convencional, orgânico e integrado, nas safras de 2010 e 2011.

Fonte: Elaboração da autora.

As características químicas apresentadas na Figura 3 indicam que as médias dos teores de acidez total (mg ácido cítrico.100g-1 de polpa), sólidos solúveis e os valores da relação SS/AT (Ratio) e do pH não apresentaram diferenças significativas entre os sistemas de produção nas safras de 2010 e 2011 . Esses valores estão dentro do esperado para essa variedade (ALVES, 2009) e concordam com o observado por Magkos et al.(2003), Ferreira et al. (2010), Winter e Davis (2006) e Luthuria et al. (2010). Amodio et al. (2007) e Ferreira et al. (2010) também verificaram que os teores de açúcares e ácidos orgânicos em frutos cultivados nos sistema de produção orgânico e convencional não apresentavam diferenças significativas.
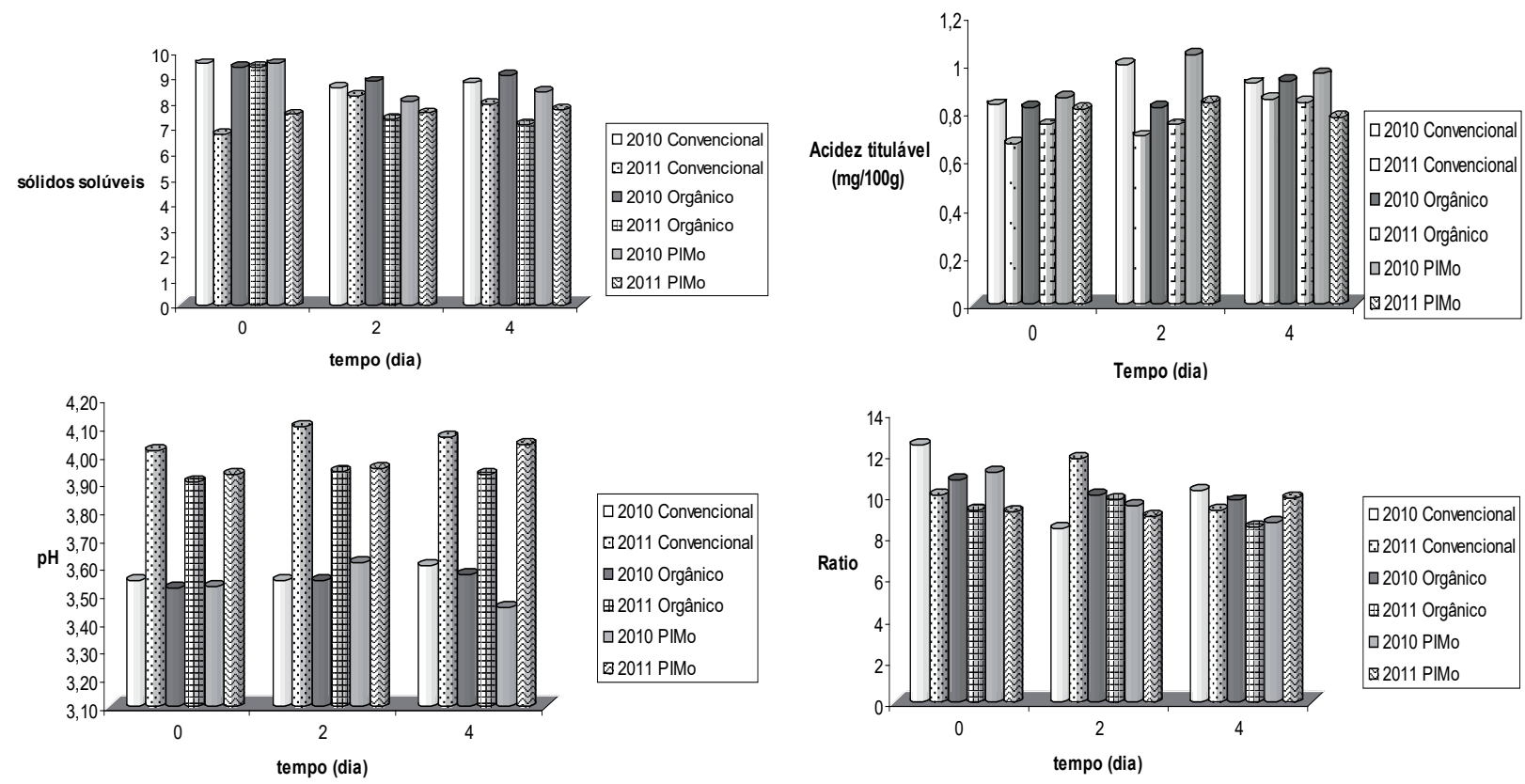

$\square 2010$ Convencional ๑ 2011 Convenciona $\square 2010$ Orgânico $\boxplus 2011$ Orgânico ๑2010 PIMo ๑ $2011 \mathrm{PIMO}$

Figura 3. Valores médios dos teores de acidez titulável e sólidos solúveis, assim como Ratio e o pH da polpa de morangos produzidos em sistema de produção convencional, orgânico e integrado, nas safras de 2010 e 2011. Fonte: Elaboração da autora. 


\title{
Conclusões
}

Os morangos produzidos nos sistemas orgânico, integrado e convencional mostraram-se iguais quanto à qualidade pós-colheita.

Os morangos orgânicos mostraram ser um alimento seguro, pois não se detectou nenhum resíduo de agrotóxicos.

Os produtos do sistema convencional se mostraram inseguros ao consumo, pois foram detectados resíduos de produtos não autorizados para a cultura e limite máximo de resíduo (LMR) acima do permitido.

Nos morangos de produção integrada, na safra 2011 , foi detectada falha no sistema de produção.

\section{Agradecimentos}

À Fundação de Amparo à Pesquisa do Estado de São Paulo (FAPESP) pelo auxílio financeiro.

\section{Quality and safety on strawberry produced under conventional, organic and integrated systems}

\begin{abstract}
Fragaria $x$ ananassa strawberry has great fruit cluster and it is commercially viable because of its attractive smell and flavor. In Brazil, strawberry has been produced under 3 systems: Conventional Crop, a traditional system which is not ruled by specific laws; Integrated Strawberry crop (PIMo in Portuguese) and Organic Production, the last two systems have volunteer access certification that are ruled by specific technical laws. The aim of this paper was to evaluate Oso Grande strawberry post-harvest quality and food safety that comes from different crop systems. We evaluated 27 - 300 to $400 \mathrm{~g}$ - strawberry samples from 9 different producers, wrapped on PET (polyethylene terephthalate) trays. We analyzed food safety, multiresidue of authorized products by Agriculture Department and some non-authorized ones which were identified by Sanitary Surveillance National Agency (ANVISA in Brazil), post-harvest quality (physics and chemical analyses). The conventional system products presented non-authorized products residue in both harvests, hence they were not safe for eating. Organic, integrated and conventional crop strawberry showed the same post-harvest quality.
\end{abstract}

Key words: Post harvest; Safe food; Shelf life; Residue.

\section{Referências}

ALMENAR, E.; CATALA, R.; HERNANDEZ-MUÑOZ, P.; GAVARA, R. Optimization of an active package for wild strawberries based on the release of 2-nonanone. LWT Food Science Technology, Amsterdam, v.42, p.587-593, 2009. doi:10.1016/j.Iwt.2008.09.009

ALVES, F.G. Comportamento pós-colheita de frutos de morangueiro mantidos sob temperatura refrigerada após a aplicação pré-colheita de produtos biológicos. 2009. 32p. Dissertação (Mestrado). Universidade Estadual de Montes Claros, Montes Claros. 
AMODIO, M.L.; COLELLI, G.; HASEY, J.K.; KADER, A. A. A comparative study of composition and postharvest performance of organically and conventionally grown kiwifruits. Journal of the Science of Food and Agriculture, Chichester, v.87, n.7, p.1228-1236, 2007. doi: 10.1002/jsfa.2820

A.O.A.C. Official methods of analysis of the Association of Official Analytical Chemists International. 16.ed., v.2, Washington: Ed. Patrícia Canniff, 1997. 850p.

ASAMI, D. K.; HONG, Y-J; BARRETT, D. M.; MITCHELL, A. E. Comparison of the total phenolic and ascorbic acid content of freeze-dried and air-dried marionberry, strawberry, and corn grown using conventional, organic, and sustainable agricultural practices. Journal of Agricultural and Food Chemistry, Washington, v.51, n.5, p.1237-1241, 2003. doi: 10.1021/jf020635c

BOURN, D.; PRESCOTT, J. A comparison of the nutritional value, sensory qualities, and food safety of organically and conventionally produced foods. Critical Review in Food Science in Nutrition, Boca Raton, v.42, n.1, p.1-34, 2002. doi:10.1080/10408690290825439

CANTILLANO, R. F .F. Sistema de produção do morango - Sistemas de produção, nov. 2005. Disponível em: http://sistemasdeproducao.cnptia.embrapa.br>. Acesso em mar. 2010.

CODEX ALIMENTARIUS, Pesticide residues in food and feed, 2013. Disponível em: <http://www. codexalimentarius.net/pestres/data/pesticides/index.html>. Acesso em: 10 out. 2013.

DANGOUR, A. D.; LOCK, K.; HAYTER, A.; AIKENHEAD, A.; ALLEN, E.; UAUY, R. Nutrition-related health effects of organic foods: a systematic review. América Journal of Clinical Nutrition, Bethesda, v. 92, n.1, p.203-210, 2010. doi:10.3945/ajcn.2010.29269

FERNANDES, V. C.; DOMINGUES, V. F.; MATEUS, N.; DELERUE-MATOS, C. Organochlorine Pesticide Residues in Strawberries from Integrated Pest Management and Organic Farming. Journal of Agricultural and Food Chemistry, WASHINGTON, v.59, n.14, p.7582-7591. 2011. doi:10.1021/jf103899r

FERNANDES, V. C.; DOMINGUES, V. F.; FREITAS, V.; DELERUE-MATOS, C.; MATEUS, N. Strawberries from integrated pest management and organic farming: phenolic composition and antioxidant properties. Food Chemistry, Oxford, v.134, n.4, p.1926-1931, 2012. doi:10.1016/j.foodchem.2012.03.130

FERREIRA, S. M. R.; QUADROS, D.A.; KARKLE, E. N. L.; LIMA, J. J.; TULLIO, L. T. FREITAS, R. J. S. Qualidade pós-colheita do tomate de mesa convencional e orgânico. Ciência e Tecnologia de Alimentos, Campinas, v.30, n.1, p. 224-230, 2010. doi: 10.1590/S0101-20612010000100033

GIAMPIERI, F.; TULIPANI, S.; ALVAREZ-SUAREZ, J. M.; QUILES, J. L.; MEZZETTI, B.; BATTINO, M. The strawberry: composition, nutritional quality, and impact on human health. Nutrition, New York, v.28, n.1, p. 9-19, 2012. doi:10.1016/j.nut.2011.08.009

JARDIM, A. N. O.; CALDAS, E. D. Brazilian monitoring programs for pesticide residues in food Results from 2001 to 2010. Food Control, Oxford, v.25, n.2, p. 607-616, 2012. doi:10.1016/j. foodcont.2011.11.001

JIN, P.; WANG, S. Y.; GAO, H.; CHEN, H.; ZHENG, Y.; WANG, C.Y. Effect of cultural system and essential oil treatment on antioxidant capacity in raspberries. Food Chemistry, Oxford, v.132, n.1, p.399-405, 2012. doi:10.1016/j.foodchem.2011.11.011 
LAIRON, D. Nutritional quality and safety of organic food. A review. Agronomy For Sustainable Development, Les Ulis, v.30, n.1, p. 33-41, 2010. doi:10.1051/agro/2009019

LEHOTAY, S. J.; KOESUKWIWAT, U.; KAMP, H. VAN DER; MOL, H. G. J.; LEEPIPATPIBOON, N. Qualitative aspects in the analysis of pesticide residues in fruits and vegetables using fast, low-pressure gas chromatography_time-of-flight mass spectrometry. Journal of Agricultural and Food Chemistry, Washington, v.59, n.14, p.7544-7556, 2011. doi:10.1021/jf104606j

LOUARN, S.; NAWROCKI, A.; EDELENBOS, M.; JENSEN, D. F.; JENSEN, O. N.; COLLINGE, D. B.; JENSEN, B. The influence of the fungal pathogen Mycocentrospora acerina on the proteome and polyacetylenes and 6-methoxymellein in organic and conventionally cultivated carrots (Daucus carota) during post-harvest storage. Journal of Proteomics, Amsterdam, v.75, n.3, p.962-977, 2012. doi:10.1016/j.jprot.2011.10.014

LUTHRIA, D.; SINGH, A. P.; WILSON, T.; VORSA, N.; BANUELOS, G. S.; VINYARD, B. T. Influence of conventional and organic agricultural practices on the phenolic content in eggplant pulp: plant-to-plant variation. Food Chemistry, Oxford, v.121, n.2, p.406-411, 2010. doi:10.1016/j.foodchem.2009.12.055

MAFFEI, D. F.; SILVEIRA, N. F. A.; CATANOZI, M. P. L. M. Microbiological quality of organic and conventional vegetables sold in Brazil. Food Control, Oxford, v.29, n.1, p.226-230, 2013. doi:10.1016/j. foodcont.2012.06.013

MAGKOS, F.; A, ARVANITI; ZAMPELAS, A. Organic food: Nutritious food or food for thought? A review of the evidence. International Journal of Food Sciences and Nutrition, London, v.54, n.5, p. 357-371, 2003. doi:10.1080/09637480120092071.

MAGKOS, F.; ARVANITI, F.; ZAMPELAS, A. Organic food: buying more safety or just peace of mind - A critical review of the literature. Critical Reviews in Food Science and Nutrition, Philadelphia, v. 46, n.1, p. 23-56, 2006. doi:10.1080/10408690490911846

MAPA - Ministério da Agricultura, Pecuária e Abastecimento. Produção Integrada. Disponível em: <http:// www.agricultura.gov.br/desenvolvimento-sustentavel/producao-integrada >. Acesso em: 10 nov. 2009.

MAPA - Ministério da Agricultura, Pecuária e Abastecimento. Agrofit. Sistema de Agrotóxicos Fitossanitário. Disponível em: <http://agrofit.agricultura.gov.br/agrofit_cons/principal_agrofit_cons > . Acesso em: 10 out. 2010.

PELAYO, R.C.; EBELER, S.E.; KADER, A.A. Postharvest life and flavor quality of three strawberry cultivars kept at $58 \mathrm{C}$ in air or air_20 kPa CO2. Postharvest Biology and Technology, v. 27, p. 171183, 2003.

SALLATO, B. V., TORRES, R.; ZOFFOLI, J. P.; LATORRE, B. A. Effect of boscalid on postharvest decay of strawberry caused by Botrytis cinerea and Rhizopus stolonifer. Spanish Journal of Agricultural Research, Madrid, v.5, p.67-78, 2007.

SANTOS, L.O.; MARTINS, R.M.; DURIGAN, J.F.; MATTIUZ, B. Técnicas de conservação Pós-colheita do Morango. Morango: conquistando novas fronteiras, Informe Agropecuário, Belo Horizonte, v.28, n.236, p. 84-87, 2007. 
SILVA, C. S.; LIMA, L.C.; SANTOS, H. S.; CAMILI, E. C.; VIEIRA, C. R. Y. I.; MARTIN, C. S.; VIEITES, R. L. Amadurecimento da banana prata climatizada em diferentes dias após a colheita. Ciência Agrotécnica, v.30, n.1, p.107, 2006.

SILVA, F. de A. S.; AZEVEDO, C. A. V. de. Principal Components Analysis in the Software Assistat-Statistical Attendance. In: WORLD CONGRESS ON COMPUTERS IN AGRICULTURE, 7, Reno-NV-USA: American Society of Agricultural and Biological Engineers, 2009. http://www.assistat.com

SOUSA, M. B. A qualidade dos pequenos frutos sob o ponto de vista tecnológico. In: COLÓQUIO NACIONAL DA PRODUÇÃO DE MORANGO E OUTROS PEQUENOS FRUTOS. 1. 2000, EAN, Oeiras. Actas... Oeiras, 2000, p. 165-170.

WINTER, C. K.; DAVIS, S. F. Organic foods. Journal of Food Science, Oxford, v.71, n.9, p.117-124, 2006. doi:10.1111/j.1750-3841.2006.00196.x

\section{Histórico editorial}

Submetido em: 01/08/2014

Aceito em: 16/12/2014 